\title{
Viewpoint: A Critical View on Smart Cities and AI
}

\author{
Daniela Inclezan \\ Luis I. Prádanos \\ Miami University, 501 E High St \\ Oxford, OH 45056 USA
}

\author{
INCLEZD@MIAMIOH.EDU \\ PRADANLI@MIAMIOH.EDU
}

\begin{abstract}
AI developments on smart cities, if not critical, risk making a flawed urban model more efficient. Instead, we suggest that AI should challenge the mainstream techno-optimistic approach to solving urban problems by dialoguing with other academic fields, questioning the dominant urban paradigm, and creating transformative solutions. We claim that doing differently, rather than doing better, may be smarter for cities and the common good.
\end{abstract}

\section{Introduction}

Urban applications of AI have received a lot of attention lately in both academic and nonacademic venues (Marvin, Luque-Ayala, \& McFarlane, 2015). The mass media especially has celebrated advances in AI as the potential panacea for pressing urban problems such as traffic congestion, growing population, environmental degradation, energy efficiency, safety, etc. This hyperbolic attention to AI-based technological fixes to urban structural problems reflects a tendency to favor a techno-optimistic framing - to take for granted that the keystone to solving societal problems lays solely in the improvement of tools, without questioning society's dominant beliefs. The techno-optimism framework has been largely disseminated by media and embraced by the general public as it is much easier to rely on technology improvements than to question ingrained epistemological inertias. However, such an approach may result in focusing on symptoms without ever targeting the root causes of social corrosion and ecological degradation (Alexander, 2014). We believe that AI should take advantage of its increasing popularity to reflect critically on its own techno-optimistic habits and strive to direct its societal impact in a truly transformative way by intervening at the root of societal problems. We focus here on the example of smart cities, but the key ideas in this paper could also illuminate other applications of AI.

\subsection{Are Smart Cities Enhancing Common Good?}

Smart cities rely on sophisticated information and communication technologies, including AI software, to improve the efficiency of existing urban processes. The social desirability and ecological viability of existing urban models is seldom questioned. Rather than embracing and perpetuating ongoing celebratory discourses about smart cities, this paper suggests that AI scholars consider approaching high-tech urbanism skeptically by attuning to the scholarship stemming from social and human sciences that are critical of techno-optimism in general (e.g., science and technology studies, ecological economics) and with the mainstream urban paradigm in particular (e.g., decolonial theory, feminist urbanism, critical urban studies, urban political ecology). This interdisciplinary dialogue would assist AI scholars in 
developing projects able to evaluate and transform the urban paradigm, rather than merely making the existing urban model "smarter" without considering the social and ecological side effects inherent in its design.

Focusing on cities is obviously relevant and paramount for any field of research that attempts to have a positive social impact. For the first time in history, more than half of the human population lives in urban settlements, and most global pressing problems are mediated by and affecting cities. Planetary urbanization is a process that is drastically altering all the live supporting systems of the earth (Rockström et al., 2009; Brenner, 2017). Modern cities rely on massive daily inputs of energy and materials from outside to sustain their infrastructures and nourish their populations. Cities also produce enormous amounts of toxic waste to be disposed elsewhere. As a result, urban metabolisms (flows of materials and energy mobilized, and waste generated, by the city to maintain its functions) are radically transforming the whole biosphere, endangering most of the living systems of the earth, including humans themselves. By depleting the source of their nourishment (fertile soil, energy stocks, clean water, climate, biodiversity, nutrients, etc.) urban metabolisms are destroying the conditions required for their future sustenance (Girardet, 2015).

If cities are part of the problem, they need to become part of the solution (Sassen, 2010). The question remains: while attempting to solve urban problems by making cities "smart", is AI merely perpetuating the ongoing dynamics of social inequality and ecological decline? Is it smart to make the current unsustainable urban model more efficient? Or is it preferable to modify the urban paradigm itself? Below are some key points to expand on these questions.

\subsection{Efficiency}

AI plays an important role in the design and development of software systems capable of managing certain urban flows and services (traffic fluidity, self-driving cars, logistics, energy usage, etc.). The gains in efficiency by themselves are assumed to be ecologically and socially beneficial. But this assumption is not necessarily true. The "rebound effect" explains why, in a consumerist, growth-oriented economic system, gains in efficiency are often lost: they lead to a lowered cost for the resource and consequently to an increase in the overall demand and consumption (Alcott, 2005). This focus on relative rather than structural efficiency (e.g. improving the efficiency of cars without considering the inefficiency of an urban model designed prioritizing individual vehicles) could be counterproductive as it ignores the immense social, ecological and economic hidden costs of scaling up and accelerating the expansion of an already unsustainable urban model.

\subsection{Learning}

In a smart city, machine learning applications relying on big data are often designed to "intelligently" mold and adapt to markets and citizens' behavior. As such, these tools may amplify counterproductive urban behaviors and an obsolete urban model that came into existence in a time when the availability of cheap and abundant energy was taken for granted. Perpetuating old patterns prevents the introduction of new urban models that are more sustainable, for instance multifunctional models, in which spaces are not segregated and differentiated by functions (work, entertainment, living, and shopping spaces). 
Multifunctional cities are less energy-intensive, decrease or eliminate car dependency, allow social and cultural mixing, promote social cohesion, improve safety and health, and are more accessible to all (Agyeman, 2013).

\subsection{Data}

Smart cities at their best claim to facilitate citizen participation in urban governance (Giffinger, Fertner, Kramar, Kalasek, Pichler-Milanovic, \& Meijers, 2007; Caragliu, Del Bo, \& Nijkamp, 2009). However, AI software dedicated to this goal only takes into consideration data acquired by digital means and thus mostly produced by citizens that have above average access to electronics. Children, low income and marginalized groups, older generations, and others may be underrepresented as they are not generating as much relevant data. Groups generating more data become more visible than others. Smart cities risk to facilitate only the lifestyle of those highly-connected privileged individuals (well-off, white, abled, professional, adult, male). If thought uncritically and learning only from technologically mediated behavior, smart cities may make more efficient the current patterns of power relations and wealth accumulation, which are already asymmetrical as well as biased in terms of race, class, age, mobility, and gender and end up increasing existing social inequality. Moreover, the reliance on digital technology for the collection of data implies a dependence on an energy intensive material infrastructure often ignored by high-tech urbanism (O'Mara, 2015).

\section{Toward a Critical AI for a Socially Desirable Smart City}

The next step is to reflect on how to make AI research socially transformative and not a mere subservient of a flawed urban paradigm. We suggest that this could be done by opening up to critical views from other fields as illustrated below. It is not our intention to provide an exhaustive list or description of all possibilities, but to suggest a few critical research avenues based on interdisciplinary synergy.

Experts in science and technology studies reflect critically on scientific and technological developments and understand that technological applications are neither neutral nor independent from the dominant socioeconomic contexts, political domains, infrastructures, and institutional cultures in which they emerge. For example, this field analyzes research funding sources and their underlying motivations, policy influence on technological developments, assumptions reproduced by the researchers' cultures and institutional restrictions, and more. It also strives to understand why certain technologies materialize while others are not even envisioned as possibilities. Insights from this field could encourage AI scholars to practice critical self-reflection and to escape the temptations of techno-optimism in their approach to smart cities.

Ecological economists analyze the flux of materials and energy mobilized by economic activity, to understand its social and ecological impacts (externalities, or hidden socioecological costs not considered by mainstream economic calculations). Chilean economist Manfred Max-Neef (1991) makes a distinction between needs and satisfactors. Human needs (food, shelter, security, meaningful social interactions, etc.) are universal, while satisfactors (how different societies meet their needs) are culturally, technologically, and historically specific. For example, societies can produce food with a method that depletes the soil, pollutes the 
water, and reduces biodiversity - the faster they do it the less chances they have to be able to meet their needs in the future - or they can produce food while enhancing the environment. Both societies use and develop different technologies (satisfactors) to meet the same need (food). Making destructive satisfactors more efficient may not be the best option. Instead, technological innovation could be better directed to design a different, more benign satisfactor. Insights from ecological economics could encourage AI to help design a truly smart city, namely, a city that satisfies needs for most citizens through satisfactors that either minimize social and ecological externalities or, even better, are socio-ecologically regenerative.

Decolonial theorists suggest asking: Who benefits and who suffers from a certain social, political, economic, or cultural system? How do power asymmetries influence economic dynamics, cultural assumptions, and dominant institutions to the benefit of some groups and at the expense of others? Who decides how a society is organized and who is excluded from the decision making process? Critical urban studies, feminist urbanism, and urban political ecology apply these questions to the urban process and design: Is it really smart to technologically refine an urban model that operates by undermining the material conditions for our biophysical survival? What exactly are smart cities supposed to facilitate, for the benefit of whom, and at what cost? Are smart cities made in the image of a specific group? Is AI thinking for, or thinking with, the citizens living in that city? Is a given smart city project promoted by critical urban planning and supported by the locals living in that city or by non-transparent technocratic/corporate/political interests?

Feminist urbanists (Peake \& Rieker, 2013), for instance, favor an urban design that facilitates the daily social reproduction of all citizens (disabled, children, elder, women, different cultures, minority groups), not just the productivity of car owners, young, single, able professionals. Cities are designed to improve livability and not only to facilitate economic transactions. As such, feminist urban designers promote users' creativity, flexibility, and modifiability, to allow every person to access the city commons and to remake the urban space according to their needs.

According to these insights from other fields, to develop an AI project related to smart cities that is truly transformative for society, researchers could consider the following suggestions:

- Learn about alternative urban models - such as transition towns (Transition Network, 2016), slow cities (Cittaslow, 2016), green infrastructure (United States Environmental Protection Agency, 2017) - and try to understand the multiple social and ecological impacts of their satisfactors.

- Increase diversity in the workforce to allow alternative views of the importance of social outcomes; include social, cultural, gender, racial, epistemological, and functional diversity.

- When forming a research team, consider inviting experts from other fields, trained to see things that AI scholars will likely miss (e.g. urban ecologists, biomimesis designers, industrial ecologists, ecological economists, decolonial scholars, science and technology philosophers, feminist urbanists, energy critical scholars, environmental humanists, and artists). 
- Explore how AI can help design circular urban metabolisms that are socially and ecologically regenerative.

- Listen to the suggestions of many stakeholders affected by the project, especially the more vulnerable ones who tend to be either overlooked or treated like problems by mainstream urban developers. Think of them as potential co-producers of urban solutions.

- Question techno-optimism. Pay attention to future potential repair and maintenance costs (Russell \& Vinsel, 2017), not only to unlimited growth and expansion (simple solutions are sometimes the best solutions).

\section{Conclusions}

If smart cities merely promote and facilitate business as usual within the existing dominant urban paradigm, they may be improving counterproductive dynamics and accelerating illconceived mechanisms. Today, we are much more efficient at depleting the Earth than we were a few decades ago. Doing differently, rather than doing better, may be smarter. Instead of learning from existing urban patterns, maybe AI needs to unlearn established inertias ingrained in the current dominant urban model to be able to design genuinely

smart - namely socially and ecologically regenerative - cities. Dialoguing with social and human sciences that are critical to the global urban processes will certainly help achieving this goal.

\section{References}

Agyeman, J. (2013). Introducing just sustainabilities: Policy, planning, and practice. Zed Books, London.

Alcott, B. (2005). Jevons' paradox. Ecological Economics, 54(1), 9-21.

Alexander, S. (2014). A critique to techno-optimism: Efficiency without sufficiency is lost. In Postcarbon Pathways Working Paper Series. Melbourne Sustainable Society Institute, Melbourne.

Brenner, N. (2017). Critique of urbanization: Selected essays. Birkhäuser, Basel.

Caragliu, A., Del Bo, C., \& Nijkamp, P. (2009). Smart cities in Europe. In Serie Research Memoranda, 48. VU University Amsterdam, Faculty of Economics, Business Administration and Econometrics. Retrieved November 2017 from https: //ideas.repec.org/p/vua/wpaper/2009-48.html.

Cittaslow (2016). International network of cities where living is good. Retrieved November 2017 from http://www.cittaslow.org/.

Giffinger, R., Fertner, C., Kramar, H., Kalasek, R., Pichler-Milanovic, N., \& Meijers, E. (2007). Smart cities: Ranking of European medium-sized cities. In Smart Cities. Vienna: Centre of Regional Science. Retrieved November 2017 from http://www. smart-cities.eu/download/smart\_cities\_final\_report.pdf.

Girardet, H. (2015). Creating regenerative cities. Routledge, New York, NY. 
Marvin, S., Luque-Ayala, A., \& McFarlane, C. (Eds.). (2015). Smart urbanism: Utopian vision or false dawn. Routledge, London, England and New York, NY.

Max-Neef, M. A. (1991). Human scale development. The Apex Press, New York, NY.

O'Mara, M. (2015). The environmental contradictions of high-tech urbanism. In Hou, J., Spencer, B., Way, T., \& Yocom, K. (Eds.), Now Urbanism. The Future City is Here. Routledge, New York, NY.

Peake, L., \& Rieker, M. (Eds.). (2013). Rethinking feminist interventions into the urban. Routledge, New York, NY.

Rockström, J., Steffen, W., Noone, K., Persson, A., Chapin, F. I., Lambin, E., ..., \& Foley, J. (2009). Planetary boundaries: Exploring the safe operating space for humanity. Ecology and Society, 14(2), 1-33. Retrieved November 2017 from http: //www. ecologyandsociety.org/vol14/iss2/art32/.

Russell, A., \& Vinsel, L. (2017). Let's get excited about maintenance!. The New York Times, July 22. Retrieved November 2017 from https://www.nytimes.com/2017/ 07/22/opinion/sunday/lets-get-excited-about-maintenance.html.

Sassen, S. (2010). Cities are at the center of our environmental future. S.A.P.I.EN.S, 2(3). Retrieved November 2017 from https://sapiens.revues.org/948.

Transition Network (2016). A movement of communities coming together to reimagine and rebuild our world. Retrieved November 2017 from https://transitionnetwork. org/.

United States Environmental Protection Agency (2017). Green infrastructure. Retrieved November 2017 from https://www.epa.gov/green-infrastructure. 